\section{Global Scientific Challenges: Perspectives from Young Scientists}

\section{by Cristina Airoldi}

An international conference was held in celebration of 75 years of the ICSU (International Council for Science) from 4-6 April 2007 in Lindau, Germany. ICSU is an international organization whose mission is to strengthen international science for the benefit of society. It takes part in the U.N. Commission for Sustainable Development, representing, together with WFEO (World Federation of Engineering Organisations), the science and technology community.

The vision of ICSU is "A world where science is used for the benefit of all, excellence in science is valued, and scientific knowledge is effectively linked to policy-making. In such a world, universal and equitable access to scientific data and information is a reality and all countries have the scientific capacity to use these...." The ICSU strategy is structured around three overlapping themes where it has historically been active:

- International Research Collaboration

- Universality of Science

- Science and Policy

The conference brought together 147 young scientists from 71 different countries, and from different research areas, to discuss some of the key challenges for science in the 21st century. The agenda was structured around four main topics:

- building bridges within the scientific community

- $\quad$ building bridges between science and the world

- working with the private sector

- $\quad$ scientific freedom and responsibility

An additional section, titled "A "Carbon Neutral" Conference: Overview of the Concept, and Discussion of Options for Offsetting Emissions from this Event," was dedicated to discussing $\mathrm{CO}_{2}$ emission-related problems. Each conferee had to pay $30 €$ (included in conference fees) to offset the greenhouse gases emitted through his/her travel and the electricity consumed at the conference venue. The conference attendees were informed that, under Dr. Daniele Cesano's (LEAD Fellow) coordination, the carbon offsetting would occur through the purchase of high-value carbon credits (carbon credits that come from a project giving a high contribution to sustain- able development), either from individual project developers or from an established emission offsetting program. During the discussion it emerged that one of the great problem with $\mathrm{CO}_{2}$ emissions is that developing countries, whose emissions will increase considerable in coming years, do not utilize advanced technologies to limit greenhouse gas emissions.

\section{Building Bridges within the Scientific Community}

From the presentations and discussions on this topic, which had two sections, international cooperation and trans-disciplinary collaboration, it emerged that the most significant problems are the following:

- Scientists working in different fields very often speak "different scientific languages."

- It is difficult to publish in journals that are "good" for all participants.

- It is hard to publish quickly, as transdisciplinary collaboration takes a lot of time. This is especially limiting for young researchers, because the number and quality of publications are particularly critically for their academic carriers.

- This kind of approach is "educationally demanding" because it is hard to bring together scientists who are experts in different disciplines (academic education is generally highly specialized and "specializing").

In conclusion, there is a great "fragmentation of knowledge" that makes it very difficult to realize collaborations between groups belonging to diverse disciplinary areas. To solve these problems it is important for scientists to develop:

- $\quad$ synthesis capacity

- methodological pluralism

- models coupling

- foresight capacity

- the ability to enjoy and develop complexity

It is important that universities:

- develop transdisciplinary programs in higher education

- $\quad$ act on supporting transdisciplinary research

- $\quad$ promote mission-oriented research

- change organizational structure

Building Bridges between Science and the World This topic was divided into discussions about public engagement and science for policy. One of the great challenge for scientists is to communicate their knowledge and discoveries to layman. In fact, scientists 
should share their knowledge with the community. They should interact not only with other investigators, but with local governments and the general population, because often information that scientists have can improve or even save the lives of people. But this task is not so easy because:

- $\quad$ scientific language is usually very difficult for a lay audience to understand

- $\quad$ some information can create panic

During discussions about this topic, it appeared clear it is necessary to develop new communication strategies. In particular, the scientific community should follow these fundamental guidelines:

1. use simple language (i.e., do not use scientific terminology)

2. speak clearly, slowly, and concisely

3. understand what the audience wants to know

4. be honest and natural

5. be entertaining, not boring

Some speakers suggested the internet as a good tool to make scientific resources available to the world. But nowadays, the public get science information mainly from the media, in particular from TV, newspapers, and radio. For this reason, engaging the media is an important part of engaging the public in disseminating science information.

Regarding the science for policy topic, the discussion began with the evidence that science, technology, innovation, and engineering are fundamental for economic growth, competitiveness, and quality of life. In addition, investments in technological capacity are critical not just for advanced countries, but for developing countries as well. The ideal model that describes the relationship between science and policy/society is the linear one, represented by the following scheme (from Pablo Guerra's presentation):

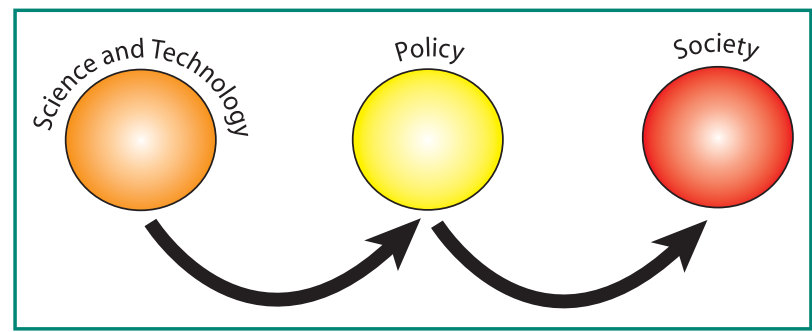

According to this model:

- $\quad$ science produces new policy-relevant knowledge

- knowledge is transferred to policy

- a decision is made
At the end of the process, society reaps the benefits of scientific knowledge through science-based policy. Unfortunately, this model does not reflect the following reality:

- $\quad$ sound decisions are based on normative components (different ethical/political frameworks)

- "society-at-large" does not exist per se (there are in fact many different groups with different interests)

- $\quad$ translation is not trivial (different languages)

- knowledge flows are multilateral (lay-knowledge, legal-knowledge, and economic knowledge, etc.)

In such a situation, science can contribute since it can mobilize resources (lobbying, education, etc) and generate interactional expertise within the policy community with the aim of providing the most comprehensive image possible. In fact, there is a need to have informed public opinion about the potential of scientific and technological knowledge, but this requires the development of a scientific culture that ensures democratic participation in the decision processes related to scientific policy. Second, it appears clear that an increase in investments in research and development is required, both in advanced and developing countries to allow science to find solutions to societal problems.

\section{Working with the Private Sector}

This section did not prove to be very interesting. Different experiences of young researchers employed in the private sector were reported, but important topics were omitted. For example, no one discussed how industry can really participate and promote science and technology development, how public-private partnerships are essential for creating new education and training models, or how industry and university research activities can be complementary and cooperation very useful for solving societal problems.

\section{Scientific Freedom and Responsibility}

This section opened with a magisterial talk by Bengt Gustafsson, who has written a book on this subject. According to Gustafsson, science and technology are among the most positive forces for change at humankind's disposal. Universal and equitable access to scientific knowledge is crucial, he said, in bridging the socio-economic divide between the North and the South of the world. For this reason, in a rapidly changing world, the Principle of Universality of Science (ICSU Statute 5, section 2.5.2) provides an important 
model of equity, nondiscrimination, and cross-cultural cooperation. However, he pointed out that not all of the impacts of science and technology are equally beneficial, nor are they universally seen to be so.

As Gustafsson sees it, the scientific community and society have to confront some great challenges:

1. Advances in genetics and the life sciences are not accepted by many because they feel threaten by the risk of nature alteration, and even though advances in genetic promise to cure disease and alleviate hunger.

2. Pollution and environmental degradation continue to be among the unintended consequences of many beneficial technologies (e.g., increasing dependence on fossil-fuel-based technologies is changing the planet climate).

3. In several countries, research into new and more deadly weapons is still being pursued.

In addition, new concerns have been raised about the ethics of research and the accountability of science to its sponsoring governments and publics, especially as more research is conducted across national political boundaries. Questions for science now seem to come, to an increasing degree, from the needs or interests of states and society, rather than exclusively from scientists' own curiosity. Moreover, there is an increasing presence of the private sector in scientific practice, as well as increased collaboration, sometimes mandated by law and policy, among universities, industry, and government. While this development has generated more resources for science and strengthened ties between research, development, and commercialization, it also carries possible risks to academic freedom and research ethics.

This conference provided a very important experience for young researchers from different countries to compare their situations, in particular to those of people who conduct research in developing countries. It was evident that we have to face diverse realities and difficulties, but a lot of problems, such as those related to scientific cooperation, collaboration, scientific freedom, and responsibility, are the same. Certainly, the goal of the conference was to sensitize young researchers to their roles and functions in society. No final solutions to discussed problems were provided.

The only negative aspect of this conference was the duration; two days appears to have been too short a time to discuss such complex topics.

Cristina Airoldi <cristina.airoldi@unimib.it> received her Bachelors degree in bio- technology in November 2003 from the University of Milano-Bicocca; she received her Ph.D. degree in chemistry, under the supervision of Prof. Francesco Nicotra, in January 2007 from the Department of Biotechnology and Biosciences.

www.icsu.org/10_icsu75/75ANNIV_Young.html

\section{Mycotoxins and Phycotoxins}

\section{by Hamide Senyuva}

On the 44th year of its establishment, TUBITAK hosted the XIIth International IUPAC Mycotoxin and Phycotoxin Symposium in the Askeri Museum in Istanbul, Turkey, from 21-25 May 2007. This symposium was the biggest ever in terms of participation, number of papers presented, and size of the scientific exhibition.

The opening ceremony of the symposium included speeches by the vice president of TÜBITAK, Ömer Cebeci, IUPAC representative Elke Anklam, and the chair of the organizing committee, Hamide Z. Senyuva. During the symposium, there were 12 main sessions with presentations from 27 invited and 2 keynote speakers who are well-known worldwide and have renowned expertise in their fields. There were 105 oral presentations and 300 poster presentations chosen by the symposium scientific committee, an exhibition of analytical instruments and food manufacturing companies' products. Moreover, workshops, satellite meetings, and many parallel meetings of international and European companies were held on the same campus.

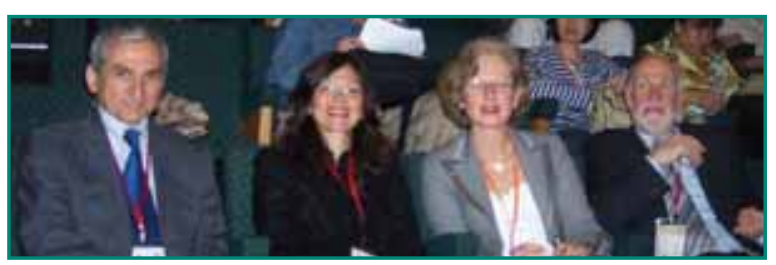

Opening Ceremony (from left): Omer Cebeci (vice president of TUBITAK), Hamide Senyuva (symposium chair), Elke Anklam (IUPAC Division of Chemistry and the Environment), and John Gilbert (chair of the Scientific Committee).

Approximately 580 participants from 65 countries attended the symposium. These researchers and representatives of universities, research institutes, governmental establishments, and industry all had concerns with mycotoxins and phycotoxins, from the 